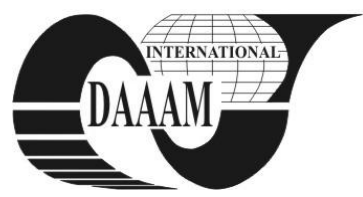

Annals of DAAAM for 2011 \& Proceedings of the 22nd International DAAAM Symposium, Volume 22, No. 1, ISSN 1726-9679 ISBN 978-3-901509-83-4, Editor B. Katalinic, Published by DAAAM International, Vienna, Austria, EU, 2011 Make Harmony between Technology and Nature, and Your Mind will Fly Free as a Bird Annals \& Proceedings of DAAAM International 2011

\title{
COMPUTERIZED CONTROL AND MONITORING OF AN ELECTRIC DRIVING SYSTEM
}

\author{
LIVINTI, P[etru] T. \& STOLERU, A[ngelo]
}

\begin{abstract}
This paper is presenting an experimental stand for computerized controlling and monitoring of an electric driving system. This stand is composed of the following elements: a static frequency converter that supplies a three-phase asynchronous motor, a tachymeter for rpm measurement a central unit and monitor for control and monitoring, and a single-phase synchronous generator for loading the threephase asynchronous motor. The data transmission from converter to P.C. is performed by means of a data serial cable $R J 45-R S 232$.
\end{abstract}

Key words: asynchronous motor, static frequency converter, digital tachymeter, serial communication, pro-drive program

\section{INTRODUCTION}

An experimental stand has been built for computerized control and monitoring of a three-phase asynchronous motor (Stoleru, 2009). This stand is composed of the following elements: a static frequency converter that supplies a threephase asynchronous motor, a digital tachymeter for rpm measurement, a central unit and monitor for control and monitoring, and a single-phase synchronous generator for loading the three-phase asynchronous motor (Livinti, 2007). The data transmission from converter to P.C. is performed by means of a data serial cable RJ 45 - RS 232. The control and monitoring of the three-phase asynchronous motor are performed through the Pro-drive program, installed in the memory's computer. For monitoring the rpm, a web camera, connected to the computer has been used. It is fixed above the digital tachymeter. In other projects, a computer equipped with a data acquisition board and encoders for measuring the running parameters have been used for controlling and monitoring the three-phase asynchronous motor. In contrast, the method being described in this paper, does not use a data acquisition board, or encoders, but allows both the control and monitoring of the parameters of the three-phase asynchronous motor through the usage of a serial communication between the static frequency converter and the computer. By making use of this solution, the costs of the control and monitoring installation of the three-phase asynchronous motor are lowered.

\section{DESCRIPTION OF THE EXPERIMENTAL STAND}

The experimental stand (Fig. 1) is composed of the following: 1- central unit; 2- monitor; 3- static frequency converter; 4- three-phase asynchronous motor; 5- single-phase synchronous generator; 6- digital tachymeter; 7- control panel; 8- web camera; 9- measuring instruments; 10- load resistor.

The central unit is used for monitoring the parameters of the static frequency converter (C.S.F.) that supplies the three-phase asynchronous motor as well as for the local control of the motor. The control unit is made by Hewlett-Packard. The monitor is an input/output peripheral that allows the visualization of the monitored parameters. The static frequency

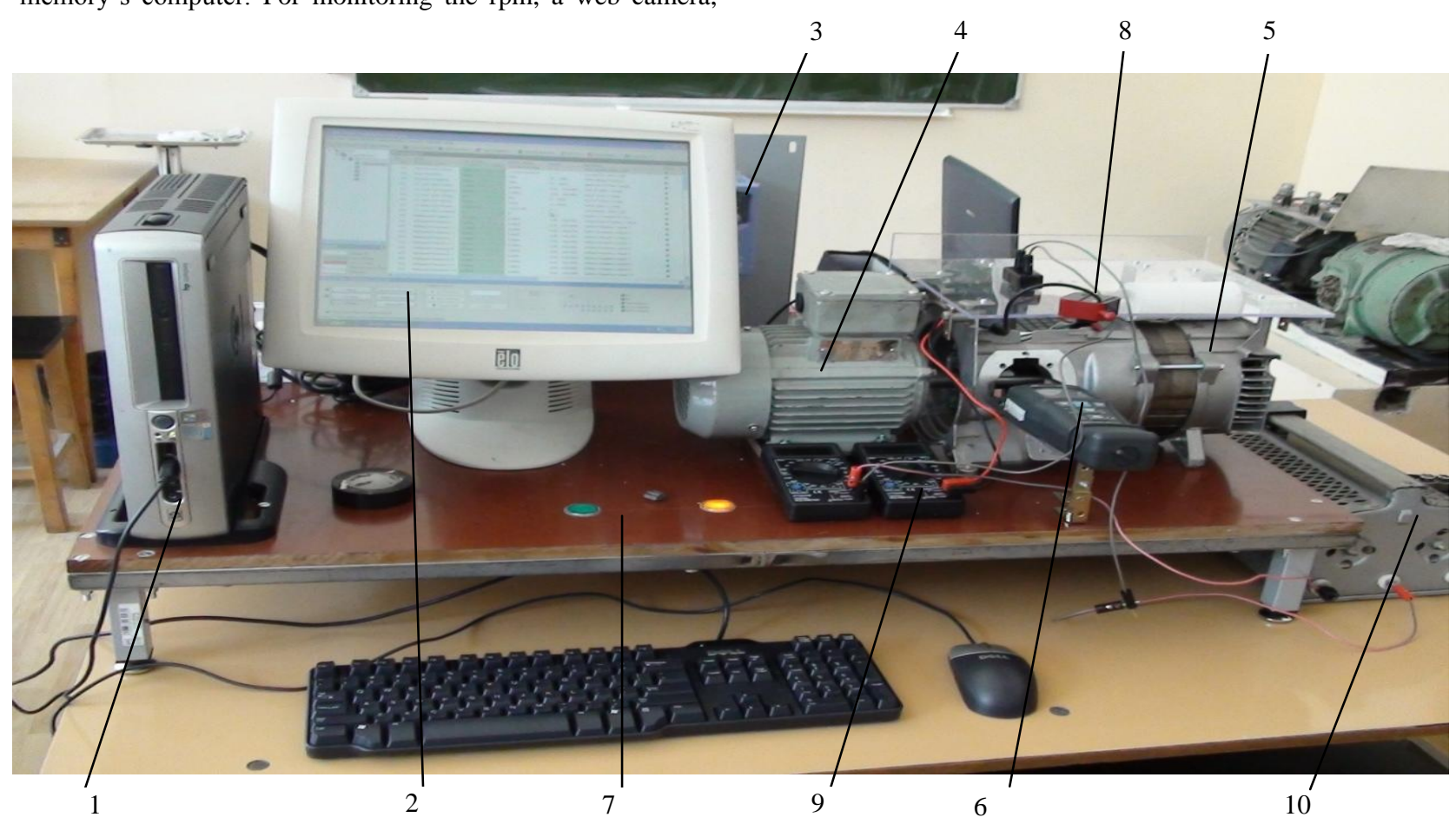

Fig. 1 Picture of the experimental stand 


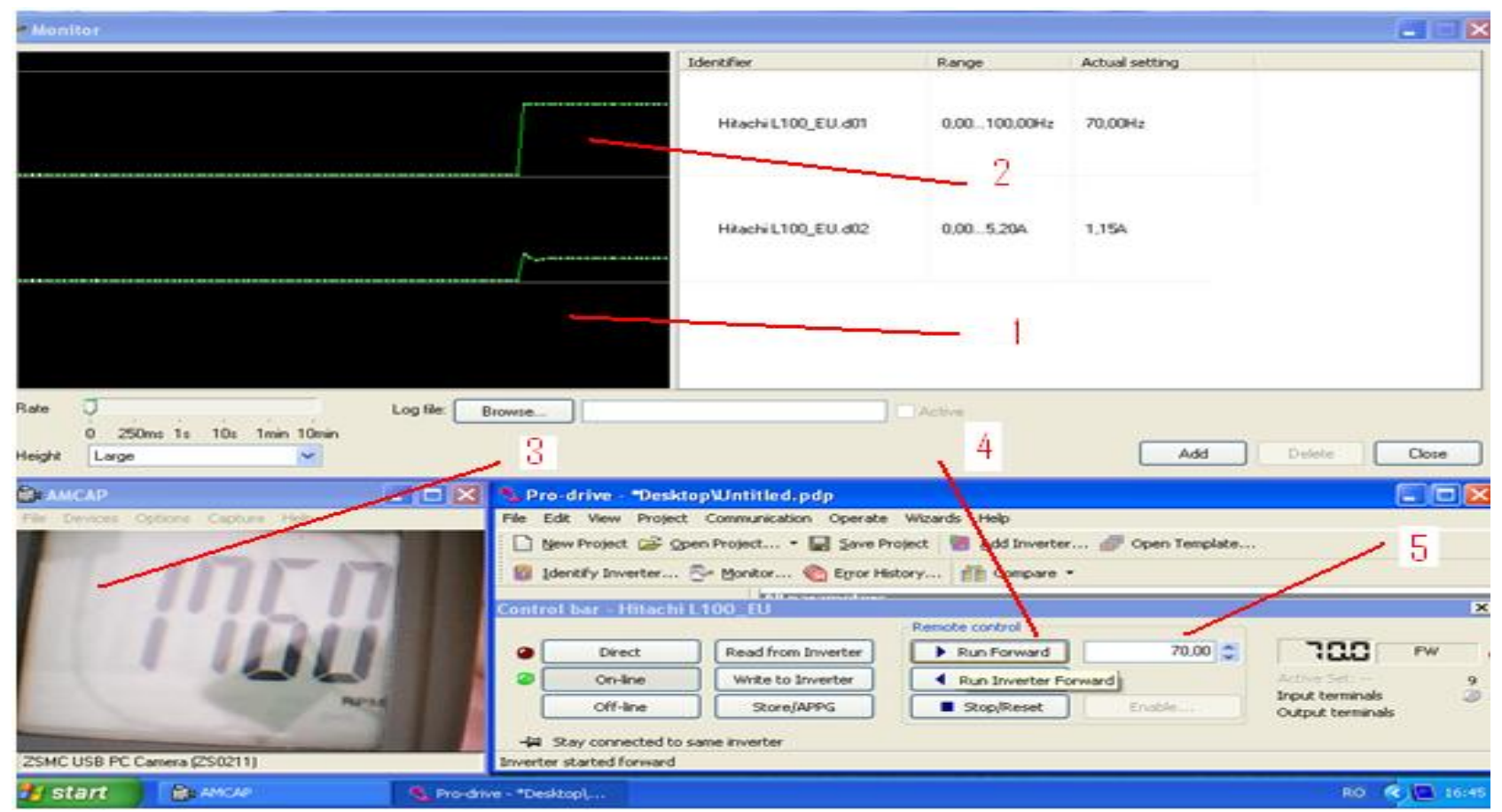

Fig. 2 Monitoring of the parameters of the three-phase asynchronous motor

converter, model L100-004NFE, is manufactured by Hitachi, (2009, Hitachi, L100). It can monitor more than 100 parameters, but we use it for monitoring the current and frequency only. The data are transmitted from the converter to P.C. by means of a data serial interface model RJ 45 - RS 232. The three-phase asynchronous motor mounted on the stand has the following parameters: rated voltage $-380 \mathrm{~V}$ A.C.; rated current $-1.06 \mathrm{~A}$; rated power $-0.37 \mathrm{~kW}$; maximum $\mathrm{rpm}-$ 1330; $\cos \varphi-0.75$. The single-phase synchronous generator is used for loading the three-phase asynchronous motor. The digital tachymeter used for monitoring the motor rpm is of VT - 8204 type, (http://www.indiamart.com/electricalselectronics/tachometers.html). The control panel is used for supplying and protecting the static frequency converter. The supply and control diagrams are shown at (Stoleru, 2009).

\section{FUNCTIONING OF THE EXPERIMENTAL STAND}

The program used for monitoring the parameters of the static frequency converter is Pro-drive, (http://www.hitachiamerica.us/products/business/inverters/support_service_sales/s oftware_dloads/prodrive_software_dload). This is delivered together with the static frequency converter C.S.F. by the Hitachi manufacturer. Through this program, the C.S.F. can be controlled and monitored with the help of a data acquisition cable. For this purpose, two stages are to be achieved:

- Set the C.S.F. manually, through the keys located on its front panel, so that it can communicate with the central unit;

- Open the Pro-drive program and select the static frequency converter L100;

- Set the communication port, COM 3 and verify that this communicates with the static frequency converter;

- Push the key "On Line" in the Pro-drive program window and wait for the central unit to get synchronized to the converter.

A limiting aspect of this stand is that the Pro-Drive program does not allow for modification of the converter's frequency when running the control and monitoring.

\section{EXPERIMENTAL DETERMINATIONS}

The rpm and current have been monitored by means of the computer mounted on the stand, and the screen showed the following online parameters, as per fig. 2: 1- Current monitoring; 2- Converter frequency monitoring; 3- Rpm monitoring; 4- Motor start/stop; 5- Modification of the frequency value. The following values of the monitored parameters have been obtained online, namely: frequency $f=$ $70 \mathrm{~Hz}$, current $\mathrm{I}=1.15 \mathrm{~A}$ and $\mathrm{rpm} \mathrm{n}=1760 \mathrm{rpm}$.

\section{CONCLUSIONS}

This paper presents an experimental stand for computerized control and monitoring of an electric driving system equipped with a three-phase asynchronous motor. The three-phase asynchronous motor is supplied from the A.C. main supply through a static frequency converter made by Hitachi. The motor rpm is measured by means of a digital tachymeter through a contactless method and monitored through a web camera connected to the computer. The static frequency converter has a serial communication with the computer for recording online the variations of the asynchronous motor parameters: frequency and current. In perspective, researches may be initiated for building a system that protects the threephase asynchronous motor through a new software program.

\section{REFERENCES}

Livinti, P. (2007): Electrical micro machines and their drive, Alma Mater Publishing, Bacau, Romania

Stoleru A. (2009): Dissertation Thesis, "Vasile Alecsandri" University of Bacau, Romania

*** (2009) Hitachi L100 Series Inverter Instruction Manual, Number NB576XC, pp. 1-5

*** (2011) (http://www.indiamart.com/electricals-electronics/ tachometers.html- VT-8204 digital tachymeter

*** (2011) http://www.hitachi-america.us/products/business/ inverters/support_service_sales/software_dloads/prodrive_s oftware_dload - Pro-drive program 